\title{
Acquiring reading in two languages: an introduction to the special issue
}

\author{
Elinor Saiegh-Haddad $\cdot$ Esther Geva
}

Published online: 13 October 2009

(C) Springer Science+Business Media B.V. 2009

The concurrent acquisition of reading in more than one language has become a prevalent reality in many parts of the world and for an increasing number of children across the globe. This is due to the rapid expansion of societal bilingualism - the byproduct of economically motivated immigration and the pluralistic composition of certain regions. The dissemination of English as the world's second language and the mostly learnt foreign language across the world has also contributed to the more or less simultaneous acquisition of reading in the indigenous language as well as in English. Added are inherently multilingual countries, like Luxembourg and many other European countries, where the concurrent acquisition of reading in multiple languages is an ordinary school enterprise. Such a widespread phenomenon warrants an in-depth analysis and understanding of the multi-faceted nature of the process of biliteracy acquisition.

Despite the pervasiveness of biliteracy as a linguistic reality of an increasing number of educational systems and a growing number of children, research into the simultaneous acquisition of reading in more than one language remains rather scarce. As a result, both theory and practice have evolved in this domain from models of monolingual monoliterate reading development dominated by the English language (Share, 2008). These models have undoubtedly contributed to our understanding of the linguistic, orthographic, contextual and socio-political factors that feature in the acquisition of reading in two languages. At the same time, they have revealed the importance of addressing theoretical questions that are unique to this dual-language context. These questions include, inter alia, cross-linguistic transfer in biliteracy acquisition, the interaction between features of the oral

\footnotetext{
E. Saiegh-Haddad $(\bowtie)$

Bar-Ilan University, Ramat-Gan, Israel

e-mail: saieghe@mail.biu.ac.il

E. Geva

OISE, University of Toronto, Toronto, ON, Canada
} 
language and features of the orthography in reading development in different languages, as well as the role of early bilingual experiences, formal and informal, in reading development. The research studies that form this collection all address theoretical questions that pertain to the concurrent acquisition of reading in more than one language. Importantly, some of these studies test such questions in novel language combinations that have never been targeted before. Others address novel questions that have thus far been under-researched. The conclusions reached by these studies converge in delineating unique features of biliteracy acquisition. These features contribute to the construction of a conceptually sound theory of reading development in bilingual and biliterate contexts. Further, these features have vital practical ramifications for reading instruction and assessment in these contexts.

The most prominent theoretical question, and probably the first to attract attention in research on biliteracy development, has been the question of transfer of knowledge between languages. The notion of transfer of linguistic skills first emerged as a key concept in the Contrastive Analysis Hypothesis (Lado, 1957). According to this hypothesis, it is possible to explain, and even to predict, which features of the second language (L2) will cause difficulty to the second language learner based on a linguistic analysis of the structures of the L2 and of the learner's mother tongue (L1). As such, the difficulty in mastering certain L2 structures may be attributed to differences between the learners' L1 and L2; similar structures will result in facilitation, or "positive transfer", whereas different structures will result in interference, or "negative transfer". While the strong version of the hypothesis could not be sustained by empirical evidence, the theoretical foundations of the Contrastive Analysis Hypothesis and the technical procedures for the contrastive study of languages were upheld.

As a behaviouristic hypothesis of L2 acquisition, contrastive analysis research has focused for many years on oral language skills, rather than on reading. The concept of transfer in reading research has surfaced rather recently. Two factors contributed to the revitalization of the concept of transfer in the domain of reading. The first is the transition in reading theory in the 1990s from top-down models, emphasizing background knowledge and higher-order reasoning and guessing skills (Goodman, 1965, 1968, 1976; Smith, 1971, 1973) to bottom-up views highlighting the importance of linguistic processing, and primarily lexical and sub-lexical processing for reading success (Adams, 1990; Goswami \& Bryant, 1990; Perfetti, 1985). This view of reading as a language problem has revamped linguistic processing as a key concept in reading and has reincarnated the question of whether literacy-related linguistic insights acquired in one language can transfer to reading in another language.

The second factor contributing to the revival of the concept of transfer in the domain of reading research was the spurt of research in the last few decades on the acquisition of basic literacy-related linguistic skills, such as lexical and sub-lexical processing, in languages other than English. This research has shown that reading models based on the development of reading in English do not reflect accurately the nature of reading acquisition in other languages, and that English ("Anglocentric") models are a byproduct of linguistic structures and orthographic representation typical of English, the "outlier" language (Share, 2008). Further, they showed that 
reading development in European languages sharing linguistic and orthographic features may be very similar (Seymour, Aro, \& Erskine, 2003). As some languages share linguistic and orthographic features and others do not, the question of whether reading-related knowledge-aspects transfer between languages has been the target of a growing number of studies involving different languages and writing systems.

The first studies addressing the question of transfer in reading have focused on the transfer of phonological awareness as a primary requisite in reading. In studies that involved English as one of the two languages under consideration, this research has demonstrated that, at least a basic level of phonological awareness is transferable between languages and that it predicts reading cross-linguistically (Durgunoglu, 2002; Genesee \& Geva, 2006; Koda, 2007). Leiken, Schwartz and Share, in this collection, provide further support for this conclusion in their study of Russian-Hebrew bilinguals. However, they also show that only specific aspects of the first language transfer (i.e., correlate with) to specific aspects of second language processing. This finding leads to the question of the underlying mechanisms of transfer and whether it is a compensatory mechanism or an inherent feature of duallanguage functioning. Specifically, (a) What determines the aspects of the first language that transfer and (b) To what aspects of the language and literacy domains of the second language?

Research evidence on the transferability of phonological awareness in reading development has led to the recognition that this aspect of language functioning is a universal component of reading in all languages (Ziegler \& Goswami, 2005). At the same time, it has been shown that phonological awareness interacts with properties of the L1 and L2 and with features of the orthography, and that its role may differ in different languages (Saiegh-Haddad \& Geva, 2008). Tong and Mc-Bride-Chang, in this collection, provide strong evidence in support of this conclusion in their study of predictors of reading in Chinese and English bilinguals.

Languages and the orthographies that map them are multilayered, and encode not only phonological, but also morphological information. Morphological processing appears to constitute an inherent aspect of language and print processing. If so, do linguistic insights about morphological structures transfer between languages? Studying this question has shown that the basic insight that words may be segmented into smaller meaningful linguistic units, that is, morphemes, may be transferred. Yet, many existing studies of cross-language transfer are correlational in nature, and do not warrant a casual connection entailed by the concept of transfer. Zhang, Anderson, Li, Dong, Wu, and Zhang, in this collection, use a tight experimental training design to test transfer of insight into the structure of compound words. In addition to supporting the validity of the notion that there is a common language competence underlying both L1 and L2 reading, the study raises two important theoretical questions regarding the extent and the direction of crosslanguage transfer. The first concerns the role of explicit instruction in enhancing cross-linguistic transfer. The second concerns the minimal conditions under which cross-linguistic transfer can be observed, and in particular the role of some (unspecified) threshold of L2 linguistic proficiency that may be essential for transfer of specific linguistic skills to take place. Ramirez, Chen, Geva, and Keifer, in this collection, provide further support of the possible role of L2 linguistic proficiency in 
determining the direction of transfer of morphological awareness. All this suggests that transfer is not a two-way free highway, and that it may be more likely to occur from the strong to the weak language, than vice versa. Perhaps, below a certain level of proficiency one may not see transfer from the L2 to the L1 (Cummins, 1979). Finally, linguistic proficiency may not be the only constraint on transfer. SaieghHaddad, Kogan, and Walters, in this collection, show that cross-linguistic differences in language representation may also constrain the transferability of linguistic insights.

Thus, reading development appears to be predicated on basic linguistic skills. Also, some literacy-related linguistic skills developed in one language transfer to the other language. This implies that bilingualism-either natural, in the form of societal bilingualism, or formal in the form of bilingual educational settingsshould not detract of the development of reading skill in one or both languages. Three studies, in this collection, target novel language-combinations and converge on this conclusion. Silven and Rubinov studied the effect of simultaneous exposure from birth to Finnish and Russian on the development of language-related literacy and showed that amount of exposure to the two home language and the frequency of language-specific social interactions explained proficiency in each language. Van der Leij, Bekebrede, and Kotterink also show that concurrent instruction in Dutch (L1) and English (L2) resulted in superior performance on most English and some of the Dutch tests. Finally, Laurent and Martinot reveal, in their study of the development of linguistic awareness in French-Occitan bilinguals, that children enrolled in a bilingual school programme have a more highly-developed phonological awareness than their monolingual peers. Yet, it takes a few years before this advantage is observed.

To sum up, studies included in this special issue consistently converge in showing that, across settings and different language combinations, reading is grounded in a shared linguistic basis. Second, they show that specific reading related linguistic insights developed in one language transfer into the other language. Clearly, the conditions under which transfer occurs are complex, and transferability interacts with (a) specific features of the linguistic and orthographic structure of the languages involved, (b) features of the learners, such as their linguistic proficiency, and the possibility of some proficiency threshold, and (c) contextual/instructional features such as explicit teaching, and amount of exposure. Collectively, these studies demonstrate that bilingual experience, whether occurring in natural settings or in formal school settings, does not affect adversely the development of language and literacy in bilingual children. However, the positive effects of early bilingualism may not be apparent at the outset.

\section{References}

Adams, M. J. (1990). Beginning to read: Thinking and learning about print. London: MIT Press. Cummins, J. (1979). Linguistic interdependence and the educational development of bilingual children. Review of Educational Research, 49, 222-251. 
Durgunoglu, A. Y. (2002). Cross-linguistic transfer in literacy development and implications for language learners. Annals of Dyslexia, 52, 189-204.

Genesee, F., \& Geva, E. (2006). Cross-linguistic relationships in working memory, phonological processes, and oral language. In D. August \& T. Shanahan (Eds.), Developing literacy in second language learners: A report of the national literacy panel on language minority children and youth (chapter 7) (pp. 175-184). Mahwah, NJ: Erlbaum.

Goodman, K. S. (1965). A linguistic study of the cues and miscues in reading. Elementary English, 42, 639-643.

Goodman, K. S. (1968). The psycholingustic nature of the reading process. In K. S. Goodman (Ed.), The psycholinguistic nature of the reading process (pp. 13-26). Detroit, MI: Wayne University Press.

Goodman, K. S. (1976). Reading: A psycholinguistic guessing game. In H. Singer \& R. B. Rudell (Eds.), Theoretical models and processes of reading (pp. 497-508). Newark, DE: International Reading Association.

Goswami, U., \& Bryant, P. (1990). Phonological skills and learning to read. East Sussex, UK: Lawrence Erlbaum Associates.

Koda, K. (2007). Reading and language learning: Crosslinguistic constraints on second language reading development. Language Learning, 57, 1-44.

Lado, R. (1957). Linguistics across cultures. Ann Arbor: University of Michigan Press.

Perfetti, C. A. (1985). Reading ability. New York: Oxford University Press.

Saiegh-Haddad, E., \& Geva, E. (2008). Morphological awareness, phonological awareness, and reading in English-Arabic bilingual children. Reading and Writing: An Interdisciplinary Journal, 21, 481-504.

Seymour, P. H. K., Aro, M., \& Erskine, J. M. (2003). Foundation literacy skills in European orthographies. British Journal of Psychology, 94, 143-174.

Share, D. (2008). On the Anglocentricities of current reading research and practice: The perils of overreliance on an "outlier" orthography. Psychological Bulletin, 134, 584-615.

Smith, F. (1971). Understanding reading. New York: Holt, Rinehart \& Winston.

Smith, F. (1973). Psycholinguistics and reading. New York: Holt, Rinehart \& Winston.

Ziegler, J. C., \& Goswami, U. (2005). Reading acquisition, developmental dyslexia, and skilled reading across languages: A psycholinguistic grain size theory. Psychological Bulletin, 131, 3-29. 